DOI 10.5216/ag.v4i9.9388

\title{
TERRITORIALIZAÇÃO DO CAPITAL: Biotecnologia, Biodiversidade e seus impactos no Cerrado ${ }^{1}$
}

\author{
TERRITORIALISATION DU CAPITAL: Biotechnologie, Biodiversite et ses \\ impacts sur le Cerrado
}

\section{CAPITAL TERRITORIALIZATION: Biotechnology, Biodiversity and their impacts on the Cerrado}

\author{
Manoel Calaça \\ Professor do curso de Geografia do Instituto de Estudos Sócio-Ambientais - IESA \\ Universidade Federal de Goiás - UFG - Brasil \\ Campus Samambaia Caixa Postal 131. \\ Goiânia - GO \\ manoelcalaca@yahoo.com.br
}

\section{Resumo}

A expansão do capitalismo no campo no cerrado está intimamente associada à adoção da biotecnologia. Esse processo implicou em profundas transformações na biodiversidade e dos saberes tradicionais produzidos e transmitidos pelas populações aqui existentes, de geração em geração. Como resultado verifica-se a substituição, espacialmente diferenciada, da biodiversidade pela agrobiodiversidade, com alterações mais profundas nos territórios dominados pelo agronegócio. Esse processo implica em perda de autonomia dos produtores rurais e maior dependência destes em relação às empresas multinacionais que detêm o domínio das tecnologias das sementes e insumos a elas associadas. Os avanços da agricultura em grande escala nas lavouras comerciais do agronegócio e da agricultura de subsistência praticada pelo campesinato constituem agrobiodiversidades que simplificam os ecossistemas e implicam em perda dos conhecimentos populares.

Palavras-chave: biodiversidade, biotecnologia, agrobiodiversidade, Cerrado, saberes tradicionais.

\section{Résumé}

L'expansion du capitalisme dans le domaine du cerrado est intimement associée à l'arrivé de la biotechnologie. Ce processus a impliqué en des profondes transformations

\footnotetext{
${ }^{1}$ Este artigo resulta do projeto de pesquisa: Biotecnologia e a Gestão Participativa da Biodiversidade: Estudos de Caso de Instituições, Conhecimento Popular e Saberes Locais no Cerrado Brasileiro, apoio do Institut de Recherche et Developpement - IRD ( França) e do projeto: Apropriação do território e dinâmicas socioambientais no Cerrado:biodiversidade, biotecnologia e saberes locais, com recursos financeiros do CNPq.
} 
non seulemente des savoirs traditionnels produits et transmis de génération en génération par les populations qui habitaient notre savane, mas aussi des changements importants de la agrobiodiversité jusqu'alors existante. Le remplacement de la biodiversité par l'agrodiversité provoque des changements très importants sur les territoires où les affaires agricoles régnent. De ce fait, les résultats de ces transformations et de ces changements spatiaux sont clairement perceptibles sur la nature. En vérité, ils impliquent non seulement en une perte d'autonomie de la part des producteurs ruraux, mais l'aussi l'accroissement de la dépendence de ceux-ci par rapport aux grandes entreprises transnationnales, surtout en ce qui concerne le domaine de la technologie appliquée à la production de semences et de produits agricoles (angrais, herbicides, machinerie, etc) associés à celles-ci. Les progrès accélérés de l'agriculture - soit-elle pratiquée à grande échelle ou celle de subsistance pratiqué par des petits agriculteurs - constituent des agrobiodiversités de 1 'espace agricole, dont les résultats les plus visibles sont la simplification - c'est-à-dire d'homogénéisation - des systèmes écologiques et la perte de connaissances populaires accquises.

Mots-clés: biodiversité, biotechnologie, agrobiodiversité, cerrado, savoirs traditionneles.

\begin{abstract}
The expansion of capitalism in the Cerrado domain is intimately associated to the adoption of biotechnology. This process resulted in profound transformations in biodiversity and in traditional knowledge that are produced and transmitted by the local existing populations, from one generation to the next. As a result, there is the substitution, spatially distinctive, of biodiversity by agrobiodiversity, having deeper alterations in the territories taken over by agribusiness. This process leads to a loss in autonomy of the rural producers and a larger dependency by these relating to the multinational companies that detain the domain of the technologies of the seeds and inputs to them associated. The large scale advances in the commercial plantations of agribusiness and of subsistence agriculture performed by the countryside peasants constitute agrobiodiversities that simplify the ecosystems and result in the loss of popular knowledge.
\end{abstract}

Keywords: biodiversity, biotechnology, agrobiodiversity, Cerrado, traditional knowledge.

\title{
Introdução
}

O processo de expansão do agronegócio no Cerrado alterou, e continua alterando, a biodiversidade em áreas inclusive prioritárias para preservação da natureza. O modelo atual de gestão, manejo e aplicação da biotecnologia na produção agropastoril 
não garante, à sociedade, mecanismos que viabilizem o desenvolvimento das atividades do agronegócio com a preservação da biodiversidade. É importante investigar como essas tecnologias podem contribuir para a preservação ambiental e indicar políticas que contribuam para o uso econômico e social do Cerrado.

As reflexões que apresentamos nesse artigo resultam da pesquisa sobre a biotecnologia, biodiversidade e os saberes das populações tradicionais do Cerrado, no Estado de Goiás. Nosso objetivo é analisar a interferência que a utilização dos conhecimentos biotecnológicos tem, na preservação da biodiversidade do Cerrado, abordando o tema da agrobiodiversidade, como resultado da aplicação da biotecnologia e dos saberes tradicionais das populações construídos historicamente.

Revisão da literatura, debates teóricos em seminários sobre o tema e trabalhos realizados a campo no Nordeste Goiano e pesquisas desenvolvidas sobre a expansão do agronegócio e do campesinato, nos últimos dez anos, embasam as reflexões aqui apresentadas.

Os produtores rurais ao substituírem a vegetação típica do Cerrado pelas variedades cultivadas, pelo agronegócio e pela agricultura camponesa, substituem também os conhecimentos produzidos pela população em séculos de interação com a natureza. Forma-se, com as práticas agrícolas, agrobiodiversidades composta de plantas cultivadas, animais criados, pastagens plantadas, ervas daninhas, micro flora e micro fauna etc, cuja composição varia de acordo com a complexidade constituída pelas associações de espécies cultivadas.

\section{A territorialização do capital no Cerrado: a biotecnologia e a biodiversidade}

Abordar o tema da biotecnologia e da biodiversidade pressupõe reflexões sobre o processo de territorialização das atividades agropecuárias no Cerrado, como parte da expansão do capitalismo no campo brasileiro. Esse processo, que se convencionou denominar de modernização da agricultura, constitui-se de importantes transformações na base biotecnológica da agropecuária.

O Brasil é um país com grandes possibilidades para o desenvolvimento da biotecnologia agrícola. De um lado, por ser um país possuidor de uma imensa 
diversidade biológica, rico em plantas, animais e microorganismos, detendo aproximadamente $20 \%$ do total existente no mundo. Em referência às plantas superiores, o país possui próximo de 55 (cinquenta e cinco) mil espécies, o que corresponde a $21 \%$ do total classificado em escala mundial. A elevada concentração de biodiversidade indica que existe um grande número de genes tropicais e de genomas funcionais disponíveis para as pesquisas biotecnológicas (VALOIS, 2001).

A conservação de plantas e animais em reservas públicas e privadas é fundamental para as pesquisas biotecnológicas, tendo em vista que estas contêm os genes que servem de base para o desenvolvimento de espécies e variedades de plantas e animais adaptados às condições naturais de cada região brasileira.

No que se refere ao Cerrado verifica-se, de um lado, o uso da diversidade biológica e a apropriação do conhecimento como base para a produção de novas variedades de plantas e animais adaptados às condições edafoclimáticas da Região Centro Oeste, objetivando a viabilidade técnica, o retorno econômico e a adequação à demanda do mercado.

A principal contribuição da biotecnologia moderna à agropecuária é a possibilidade de criar novas espécies a partir da transferência de genes entre duas outras distintas. Essa transferência visa ao desenvolvimento de uma planta com atributos de interesse econômico, como é o caso das plantas resistentes a vírus ou a pragas (SILVEIRA; BORGES; BUAINAIN, 2005, p. 102).

Os avanços das novas tecnologias no mundo resultam de pesquisas realizadas por empresas privadas do ramo da produção e comercialização de sementes e insumos agrícolas e por instituições públicas de diferentes países. Geram novas variedades de animais e vegetais, adaptadas a condições ambientais antes adversas ao cultivo de determinadas espécies. No caso da região Centro Oeste, onde predomina a vegetação típica do Cerrado, de clima tropical e com predominância de solos ácidos, que antes eram considerados impróprios para a agricultura comercial, tornou-se uma das principais áreas produtoras de grãos, em razão da aplicação dos conhecimentos biotecnológicos produzidos a partir da Revolução Verde.

Atualmente o Cerrado constitui-se em uma das áreas mais importantes de expansão do cultivo de cana-de-açúcar, para produção de açúcar e álcool, graças às pesquisas realizadas por empresas privadas, pela Empresa Brasileira de Pesquisas Agropecuárias - EMBRAPA, universidades e por outras instituições públicas do gênero. 
Segundo Borém e Santos (2001), de 1987 a 2000 foram realizados, em 45 países, mais de 11000 ensaios de campo com Organismos Geneticamente Modificados, envolvendo mais de 81 cultivos, destacando-se algodão, batata, canola, milho, tomate, soja. As características genéticas introduzidas visam a tolerância a herbicidas, resistência a insetos e vírus, e mudanças na qualidade do produto tendo em vista atender aos interesses do mercado.

A introdução de sementes geneticamente modificadas e de outros avanços da engenharia genética constitui-se em uma nova revolução no campo da produção agropecuária e da preservação da biodiversidade. Isso parece contraditório, no entanto, depende do uso que se dá a esses conhecimentos. A questão referente a aplicação da biotecnologia, na agricultura e na pecuária, não está no conteúdo científico produzido mas no uso político desse conhecimento monopolizado por empresas multinacionais, que controlam a comercialização e o uso das variedades produzidas e os insumos necessários ao seu cultivo.

\section{A biotecnologia e a agrobiodiversidade no Cerrado}

A domesticação de animais e plantas é um processo antigo que remonta ao período em que o homem foi gradativamente substituindo a coleta, a caça e a pesca, pelo cultivo de plantas e criação de animais para o consumo. O desenvolvimento da agricultura e do sistema de criação de animais transformou a relação das sociedades humanas com a natureza. A domesticação implicou em alterações genéticas das plantas e animais adaptando-se e se apropriando daqueles que atendiam às demandas humanas, tornando-os cada vez mais dependentes do homem.

A agrobiodiversidade, ou diversidade agrícola, constitui uma parte importante da biodiversidade e engloba todos os elementos que interagem na produção agrícola: os espaços cultivados ou utilizados para a criação de animais domésticos, as espécies direta ou indiretamente manejadas, como as cultivadas e seus parentes silvestres, as ervas daninhas, os parasitas, as pestes, os polinizadores, os predadores, os simbiontes (organismos que fazem parte de uma simbiose, ou seja, que vivem com outros) etc., e a diversidade genética a eles associada - também chamada de diversidade intraespecífica, ou seja, dentro de uma mesma espécie. A diversidade de espécie é chamada de diversidade inespecífica (SANTILLE, 2009, p. 92). 
A análise da aplicação dos conhecimentos biotecnológicos na agricultura é fundamental para a compreensão da agrobiodiversidade nos padrões atuais, tanto aquela praticada pelo agronegócio como pelo campesinato.

A agrobiodiversidade resulta, portanto, de um processo de interação homemnatureza em suas múltiplas dimensões, que implica na produção de sistemas naturais com forte intervenção humana, pois as espécies de plantas e animais têm seus ciclos produtivos alterados para se ajustá-los aos interesses da humanidade. Nesse sentido, a biotecnologia, a biodiversidade e agrobiodiversidade, são partes constitutivas de um mesmo processo, pois as espécies animais e vegetais se transformam e são transformadas pelo interesse do homem.

[...] A agrobiodiversidade é essencialmente um produto da intervenção humana sobre os ecossistemas: de sua inventividade e criatividade na interação com o ambiente natural. Os processos culturais, os conhecimentos, práticas e inovações agrícolas, desenvolvidos e compartilhados pelos agricultores, são um componente-chave da agrobiodiversidade. As práticas de manejo, cultivo e seleção de espécies, desenvolvidas pelos agricultores ao longo dos últimos 12 mil anos, foram responsáveis, em grande parte pela enorme diversidade de plantas cultivadas e de agroecossistemas e, portanto, não se pode tratar a agrobiodiversidade dissociada dos contextos, processos práticas culturais e socioeconômicas que a determinam e condicionam. Por isso, além da diversidade biológica, genética e ecológica, há autores que agregam um quarto nível de viabilidade: o dos sistemas sócioecnômicos e culturais que geram a diversidade agrícola. (Grifo nosso). (SANTILLE, 2009, p. 94).

A incorporação da biotecnologia na agricultura goiana implicou em um processo acelerado de substituição da "biodiversidade biológica", presente nas diversas fitofisionomias do Cerrado, pela "agrobiodiversidade" produzida com a utilização da biotecnologia na agropecuária e na silvicultura. Ou seja, as lavouras comerciais desenvolvidas pelo agronegócio ou a agricultura de subsistência praticada pela agricultura camponesa, constituem-se em agroecossistemas, com diversidade de plantas e animais, inferior a da biodiversidade biológica. São geossistemas muito mais simples, portanto, com menor diversidade de plantas e animais, mais dependentes de insumos agroquímicos e do controle e intervenção humana para completar seu ciclo. 
A agrobiodiversidade resulta então do conhecimento tradicional, constituído a partir da relação do homem com a natureza que, ao longo do tempo, aprendeu a cultivar e adaptar plantas e animais aos seus interesses e necessidades. ${ }^{2}$ Esses mesmos saberes são utilizadas pelas empresas e instituições de pesquisa para produzir conhecimentos científicos e tecnológicos para o desenvolvimento de espécies e variedades de plantas e animais adaptados ao cultivo em larga escala de interesse do agronegócio - a biotecnologia.

\begin{abstract}
A biotecnologia pode ser definida como um conjunto de técnicas de manipulação de seres vivos ou parte destes para fins econômicos. Esse conceito amplo inclui técnicas que são utilizadas em grande escala na agricultura desde o início do século XX, como a cultura de tecidos, a fixação biológica de nitrogênio e o controle biológico de pragas. Mas o conceito inclui também técnicas modernas de modificação direta do DNA de uma planta ou de um organismo vivo qualquer, de forma a alterar precisamente as características desse organismo ou introduzir novas. A técnica de transferência e modificação genética direta, conhecida como engenharia genética ou tecnologia do DNA recombinante, mais a genômica, ficaram conhecidas como "biotecnologia moderna", em contraposição à "biotecnologia tradicional ou clássica", que inclui as técnicas tradicionais, que manipulam seres vivos sem manipulação genética direta (SILVEIRA; BORGES; BUAINAIN, 2005, p. 102).
\end{abstract}

A biotecnologia proporcionou, ao agronegócio, alterações no padrão técnico de produção à custa de maior dependência das tecnologias empregadas e dos insumos necessários ao desenvolvimento das atividades agrícolas e pastoris. A agricultura moderna reduz a maturidade dos ecossistemas e a diversidade de espécies animais e vegetais, e simplifica os "complexos e entrelaçados ciclos de sustentação da vida que, em razão disso, entram em curto circuito. $\mathrm{O}$ exemplo mais extremo de tal efeito é a conversão dos ecossistemas tropicais em plantações ou fazendas de monocultura" (DREW, 1986, p. 147).

A agrobiodiversidade no Cerrado goiano transformou-se profundamente ao longo dos últimos cinquenta anos. Até 1960-70 o uso da terra, predominante nos Estados de Goiás e Mato Grosso, era para a pecuária extensiva ${ }^{3}$ e agricultura de

\footnotetext{
${ }^{2}$ Um exemplo é o de um camponês do município de Crixás, que desenvolveu uma técnica para A produção de muda de pequi para o plantio em sua propriedade, verificado em trabalho de pesquisa realizado no dia 26 de maio de 2009.

${ }^{3}$ Com baixos níveis de investimento de capital e uso predominante de pastagens nativas.
} 
subsistência, ${ }^{4}$ realizada dominantemente com a aplicação dos saberes tradicionais produzidos pelos produtores.

No período de 1970-2005 verifica-se a substituição das áreas florestadas do Cerrado e das pastagens naturais pelas plantadas e por grãos, algodão e cana e a expansão dos assentamentos rurais destinados à agricultura familiar. As superfícies suavemente onduladas foram ocupadas por projetos financiados pelo PRODECER e destinados à produção agrícola diversificada. Com a expansão das agroindústrias expandiu-se também o plantio de eucalipto, que complementou esse processo. No estado de Goiás, as florestas de eucalipto aumentaram de 44.114 ha, em 2004, para 56.181, em 2008, aumento de 28,94\% no período. No Estado de Mato Grosso passou de 42.417 ha para 58.580 há, aumento de 38,10\% (ABRAF, 2009).

A partir de 2005 verifica-se a expansão do cultivo de cana-de-açúcar em áreas de pastagens e grãos com fortes impactos na biodiversidade do Cerrado. De um lado observa-se a substituição de lavouras de soja, milho, algodão, agricultura de subsistência etc. e de outra a ocupação de áreas consideradas prioritárias para a conservação da diversidade biológica em área de vegetação nativa (figura. 01). Segundo o Instituto Sociedade, População e Natureza - ISPN (2007), no período de 2006-2007, cerca de 142 mil ha de Cerrado prioritário para conservação foram convertidos em canaviais.

Esse processo, no Brasil, foi designado de modernização da agricultura e, da mesma forma como no restante do país, está sendo implantado no território goiano de forma desigual e combinada. Verifica-se que as regiões do estado articuladas com o centro dinâmico do país incorporam as novas tecnologias e a partir daí é difundida para o restante do Estado.

Portanto, é espacialmente diferenciado, pois não é incorporado de forma igual em todos os lugares ao mesmo tempo e da mesma forma, varia em razão dos níveis de capitalização dos produtores e das condições locais de infraestrutura, logística, solo, topografia, disponibilidade de terras que ofereçam condições de lucratividade por atividades do agronegócio ou agricultura de mercado.

\footnotetext{
${ }^{4}$ Destinada ao autoconsumo, com excedente destinado ao mercado.
} 


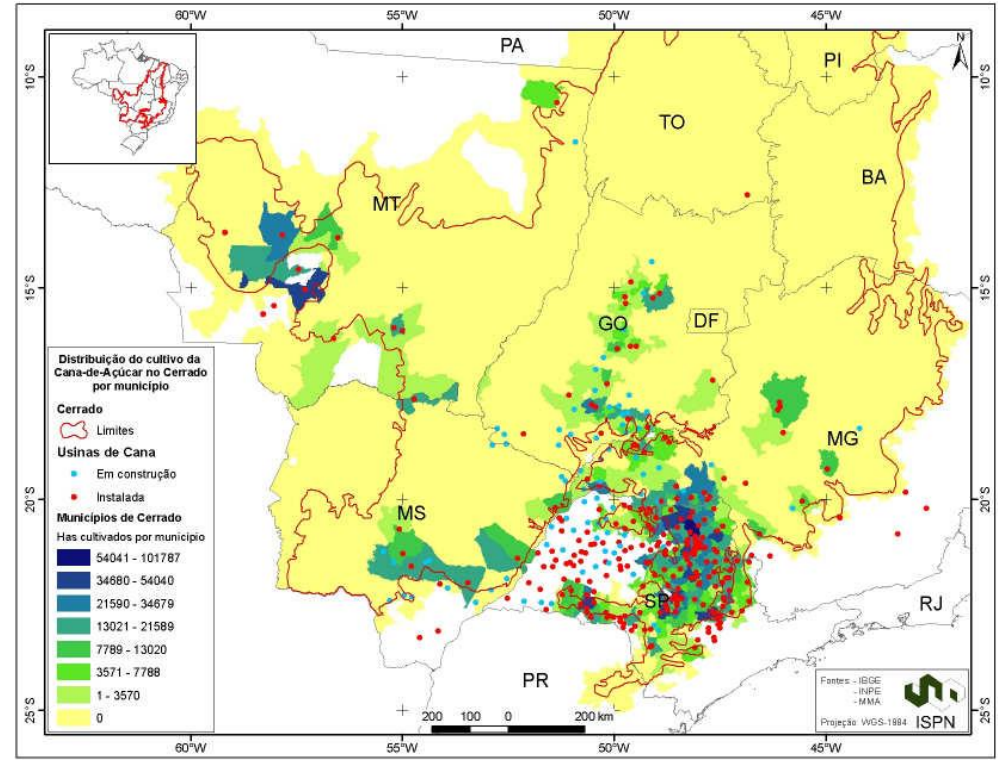

Figura 1 - Mapa da distribuição do cultivo da cana-de-açúcar no Cerrado por município e indicação das usinas instaladas e em construção, 2007. Fonte: Instituto sociedade, população e natureza. Cana de açúcar avança sobre áreas prioritárias para conservação do Cerrado. Brasília: ISPN, 2007. Pág. 11.

A tendência é de padronização do processo produtivo para atender as demandas impostas pelo mercado, no entanto, a apropriação das novas tecnologias no Brasil gera diferenciações espaciais que se reproduzem regionalmente. Os reflexos para a biodiversidade seguem o mesmo padrão espacial. Esse processo associado ao debate, pela revisão do Código Florestal Brasileiro de 1965, tem como um dos temas institucionais e ambientais mais polêmicos a questão da Reserva Legal Extrapropriedade, ${ }^{5}$ que tende a refuncionalisar os espaços, transformando áreas atualmente impróprias para o cultivo de lavouras comerciais em áreas de preservação ambiental. Há

\footnotetext{
${ }^{5}$ Portaria 01/ 2001 da Agência Ambiental do Estado de Goiás - Art. $4^{\circ}$ - A área da reserva legal extra propriedade deverá ter as características definidas por:

I - localização:

a) microrregião definida conforme classificação do Instituto Brasileiro de Estatística e Geografia - IBGE; b) - bacias hidrográficas;

\section{II - área:}

a) - quando a reserva legal extra propriedade se situar dentro da mesma micro região da matriz, sua área deverá corresponder a $25 \%$ (vinte e cinco por cento) do total da área da matriz. b) quando a reserva legal extra propriedade se situar dentro da mesma bacia hidrográfica, mas fora da micro região, sua área deverá corresponder a $30 \%$ (trinta por cento) do total da área da matriz. $\S 1^{\circ}$ - A área da reserva legal extra propriedade deverá ser nativa e não antropizada. $\S 2^{\circ}$ - As áreas da reserva legal extra propriedade determinadas neste artigo deverão ser computadas independentemente das áreas de reserva legal já existentes na propriedade matriz. $\S 3^{\circ}$ - As áreas deverão ser plotadas e devidamente demarcadas em levantamento topográfico.
} 
dois aspectos a serem considerados: de um lado possibilita que a biodiversidade biológica seja substituída por agrobiodiversidades, na medida em que a compensação financeira viabilize esse procedimento; por outro lado garante a preservação de áreas até agora inadequadas para o uso agrícola, como as áreas serranas do Nordeste goiano.

Verifica-se que o processo de simplificação da biodiversidade pelas atividades agrícolas é implantado em diferentes escalas de produção. Ele atinge desde as unidades de produção camponesa até as grandes empresas. O que os diferenciam são os níveis de incorporação dos conhecimentos tecnológicos que variam desde a utilização das técnicas da agricultura de precisão, equipamentos de última geração, produtos resultantes das pesquisas de engenharia genética, até as técnicas mais simples, gerando impactos diferenciados na biodiversidade, nas atividades econômicas, culturais e nos saberes das populações tradicionais.

Esse processo promove gradativamente a incorporação desses novos conhecimentos e altera as práticas agrícolas, as relações sociais de produção, a interação com a natureza, modificando as práticas dos camponeses e dos agricultores tradicionais do Cerrado. Resulta daí uma diferenciação espacial da agrobiobiodiversidade no Cerrado, em razão dos níveis e da intensidade de incorporação das técnicas de cultivo de plantas e da criação de animais, apropriados pelos atores sociais envolvidos no processo produtivo.

Até o presente, as novas tecnologias implicaram na inserção do Estado de Goiás no circuito da produção mundial e de comodities agrícolas, pelo agronegócio, e na desarticulação dos saberes de camponeses e agricultores tradicionais, pela simples introdução das sementes melhoradas.

O agronegócio abarca o conjunto de atividades que concorrem para a elaboração de produtos agroindustriais, desde a produção de insumos até o produto final. Nesse sentido, e tal como reconhecido pela ampla literatura sobre o tema, o agronegócio congrega as ações de produção, distribuição de suprimentos agrícolas, operações de produção nas unidades agrícolas, armazenamento, processamento e distribuição de produtos, envolvendo, portanto, as empresas que produzem, processam, comercializam e distribuem produtos agropecuários, agroflorestais e agroindustriais (GARLIPP, 2003, p.5). 
A expansão da produção agrícola pelo agronegócio em Goiás teve o seu início na década de 1970, no Sudoeste Goiano, e foi gradativamente se expandindo para outras regiões do Estado, que dispõem de topografia plana, infraestrutura, logística, incentivos públicos, facilidade para escoamento da produção, mão-de-obra etc.

A lógica da produção do agronegócio gerou, e continua gerando, de um lado a destruição de ecossistemas complexos, pois se realiza em grandes extensões territoriais e substitui a vegetação nativa por espécies agrícolas de valor comercial como a soja, o milho, o algodão, a cana-de-açúcar etc. Essas culturas resultam de espécies produzidas como parte dos avanços das pesquisas biotecnológicas, assim constituem-se em agrobiodiversidades exógenas e simplificadas, que dependem, ao contrário da biodiversidade natural, de controle químico de pragas e doenças, pelas plantas melhoradas geneticamente ou por mecanismos da engenharia genética que produz variedades que contém em seu gene a defesa contra o ataque de pragas.

Esse processo de reinvenção da natureza no estado de Goiás gera fortes impactos ambientais, sociais, culturais e econômicos, alterando a dinâmica socioterritorial do lugar que recebe novos atores sociais, promove intensa mobilidade do capital e do trabalho em razão das demandas criadas, gerando diferenciações espaciais e a coexistência de diferentes temporalidades.

Verifica-se que a incorporação de tecnologias agrícolas inovadoras é mais intensa e dominante nos municípios do Centro-Sul do Estado de Goiás, com maiores impactos na biodiversidade. Por outro lado, à medida que se afasta do Sul do Estado em direção ao Norte verificam-se níveis diferenciados de absorção das técnicas da agricultura moderna.

A figura 02 indica que as áreas com maiores extensões de vegetação nativa situam-se no nordeste do Estado, enquanto as áreas com níveis mais elevados de devastação estão situados no Centro-Sul do estado (Figura 03). Segundo Sano et al. ( 2008), esse fato deve-se a topografia da região.

Pesquisas recentes apontam que a expansão do agronegócio, principalmente soja, milho e cana e a construção de usinas hidroelétricas se constituem nas principais ameaças ao Cerrado. Segundo Barroso (2009, s/p), “A devastação do cerrado é da ordem de $1 \%$ a $1,5 \%$ ao ano, [...]. O agronegócio é a força de devastação do bioma. 


\section{CATELIÊ GEOGRÁFICO REVISTA ELETRÔNICA}

Soja, cana milho, algodão fazem parte de uma dinâmica avançando um sobre o outro conforme as determinações do mercado."

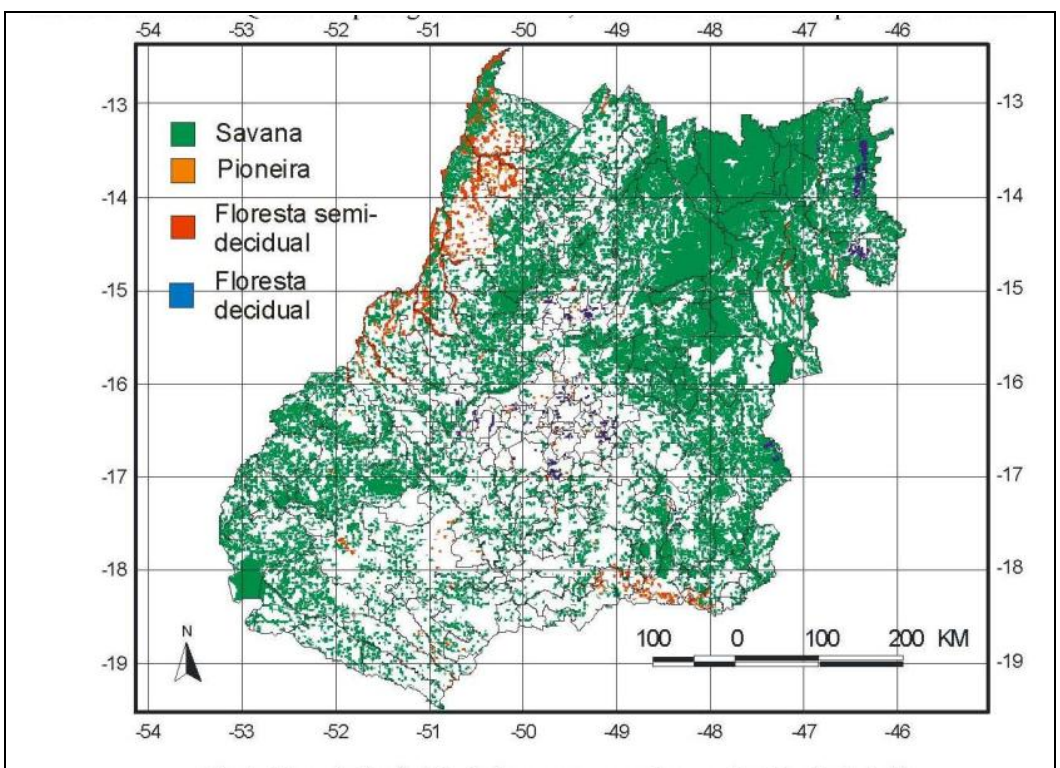

Figura 2 - GOIAS - Distribuição espacial da vegetação nativa. (adaptado) Fonte: SANO, et al., 2008.

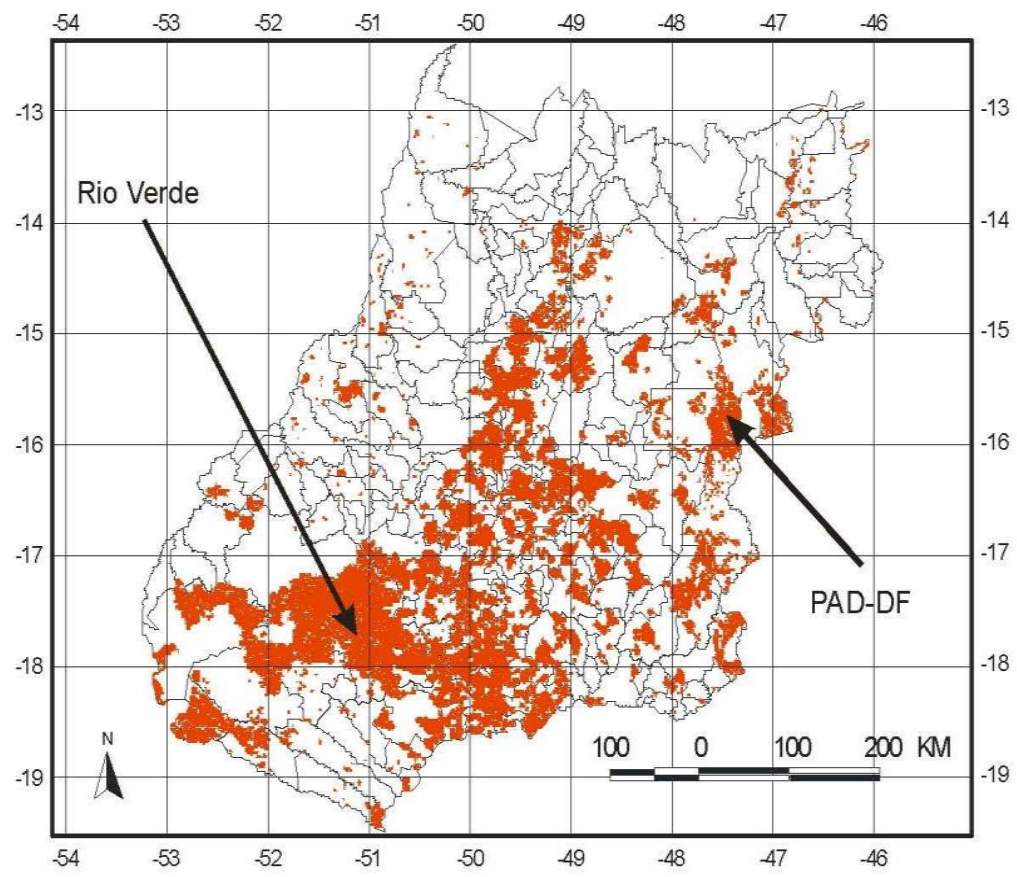

Figura 3 - Distribuição do uso agrícola do território, por Município. (Adaptado). Fonte: SANO et al., 2008. 
A devastação do Cerrado é uma realidade. A substituição da flora e da fauna por lavouras e pastagens - a agrobiodiversidade - (Quadro 01) ${ }^{6}$ implica em transformação de modos de vida, de saberes populares, de conhecimentos produzidos pela sociedade local na interação com a natureza. Esse processo implica na substituição de práticas construídas ao longo do tempo e transmitidas de geração em geração, que deixam de serem utilizadas em razão da racionalidade oferecida pela biotecnologia. Em nome do aumento da produtividade, cria-se a dependência de sementes e insumos produzidos pelo mercado, em detrimento das experiências na produção de sementes crioulas, produzidas pelas populações do Cerrado, que praticamente já se perdeu. O município de Crixás, situado na Microrregião Nordeste do Estado o Movimento dos Pequenos Agricultores, está realizando esforços para a recuperação dessas práticas.

Quanto mais avançadas são as tecnologias empregadas na produção agrícola, maiores são os níveis de substituição da vegetação nativa por espécies exógenas, de interesse comercial. A pecuária também contribui nesse processo e precisa ser melhor analisada, pois emprega as mesmas técnicas de cultivo das lavouras, desde o preparo do solo, até o plantio de sementes melhoradas de capim, adubos, uso de defensivos agrícolas e agroquímicos para combate as pragas nas pastagens (figura 4. Enquanto os municípios de Crixás e Cavalcante estão entre aqueles com menos de um por cento de seus territórios utilizados para atividades agrícola (figura 5), Rio Verde e Anápolis, situados no Centro-Sul do Estado, tem mais de $70 \%$ da superfície utilizada para o plantio de lavouras (figura 6). 
QUADRO 01 - GOIÁS: Produtos cultivados, 2010.

\section{Culturas permanentes de longa duração ${ }^{7}$}

\begin{tabular}{|l|l|}
\hline Abacate & Abacaxi \\
\hline Acerola & Cana-de-açúcar \\
\hline Banana & Mandioca \\
\hline Borracha & \multicolumn{1}{|c|}{ - } \\
\hline
\end{tabular}

\section{Culturas temporárias de curta duração ${ }^{4}$}

\section{Coco-da-bahia}

Figo

Fruta do Conde

Goiaba

Laranja

Limão

Mamão

Manga

Maracujá

Marmelo

\section{Palmito}

Pupunha

Tangerina

Urucum

Uva de mesa

Uva para vinho

\begin{tabular}{l|l}
\hline- & \\
\hline- & \\
\hline- & \\
\hline
\end{tabular}

\section{Culturas temorárias de} curta duaração ${ }^{4}$
Silvicultura ${ }^{8}$

\begin{tabular}{|l|l|}
\hline Açafrão & Eucalipto \\
\hline Abóbora & Pinus \\
\hline
\end{tabular}

Alho

Amendoim

Arroz de serqueiro

Arroz irrigado

Batata doce

Batata inglesa

Cebola

Ervilha

Feijão

Fumo

Gergelim

Girassol

Mamona

Melancia

Milho

Milho de pipoca

Soja de serqueiro

Soja irrigada

Sorgo granífero

Tomate de mesa

Tomate industrial

Trigo

Fonte: BRASIL. Levantamento Sistemático da Produção Agrícola - IBGE, 2008.

Disponível em: www.ibge.gov.br e FIDELIS, Alex Camargo; LIMA, João Donizete.

Disponível em:

http://www.uff.br/vsinga/trabalhos/Trabalhos\%20Completos/Alex\%20Camargo\%20Fidelis.pdf Org. Manoel Calaça.

\footnotetext{
${ }^{7}$ Informações do Levantamento Sistemático da Produção Agrícola - IBGE, 2009

8 Dados constantes em FIDELIS, Alex Camargo; LIMA, João Donizete. Disponível em: http://www.uff.br/ vsinga/trabalhos/Trabalhos\%20Completos/Alex\%20Camargo\%20Fidelis.pdf
} 


\section{CATELIÊ GEOGRÁFICO REVISTA ELETRÔNICA

Esses últimos se situam numa região onde os índices de preservação ambiental estão entre os menores do Estado.
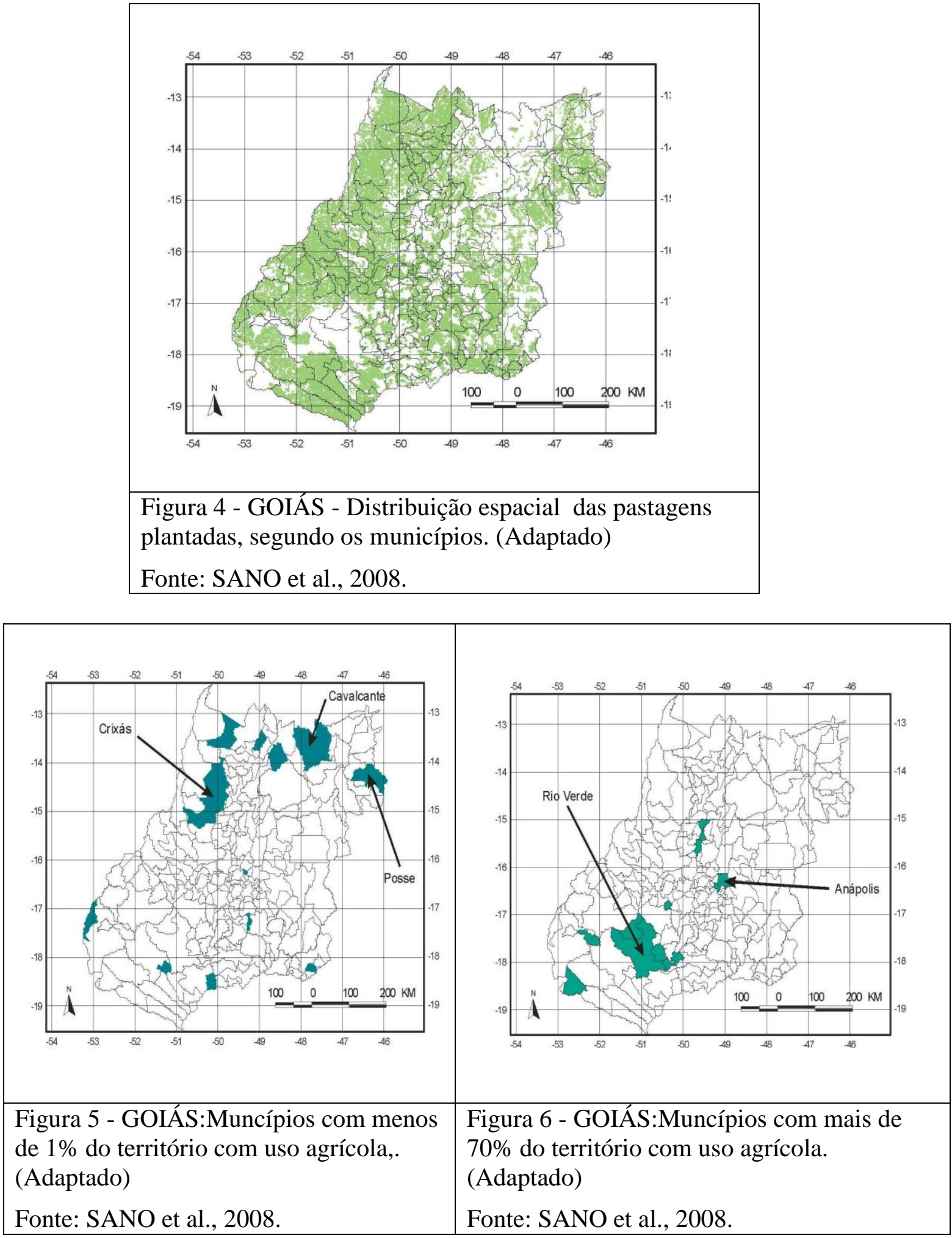


\section{Conclusão}

A pesquisa sobre os avanços da biotecnologia e seus impactos na biodiversidade do Cerrado e nos saberes tradicionais das populações nos permite compreender, com base na análise realizada nesse texto, que a aplicação dos conhecimentos biotecnológicos provoca transformações espacialmente diferenciadas no Estado de Goiás.

No que se refere aos saberes populares e as mudanças nas práticas agrícolas, verifica-se certa escala de homegeinização imposta pela difusão e utilização das sementes "melhoradas" e geneticamente modificadas, e os insumos a elas associados, por todos os segmentos de produtores rurais.

O que diferencia esse processo é o tipo de produto cultivado, a escala da produção e o modo de vida do produtor. Para os agentes do agronegócio, a aplicação dos conhecimentos biotecnológicos destina-se ao atendimento das demandas do mercado, portanto, são produtores de mercadorias, cujo cultivo oscila de acordo com a maior capacidade de remuneração em cada momento. Ao contrário para os camponeses, cuja produção destina-se primeiramente à subsistência, a apropriação da biotecnologia implica em perda de conhecimentos e práticas agrícolas produzidas ao longo do tempo e transmitidas pelas gerações, como o caso das sementes crioulas e as práticas de trabalho coletivo de ajuda mútua.

Para ambos os segmentos de produtores, esse processo implica em perda de autonomia do produtor, que se torna cada vez mais dependente das empresas multinacionais produtoras de sementes e insumos. No caso das sementes transgênicas, a empresa que tem domínio da tecnologia cobra dos produtores $2 \%$ da produção a título de royalty pela patente da tecnologia.

Por fim, os avanços da agricultura em grande escala implicam em perda de biodiversidade, pela substituição da biodiversidade pela agrobiodiversidade, tanto pelas lavouras comerciais do agronegócio como pela produção de subsistência do campesinato, reduzindo as áreas de vegetação nativa do Cerrado. 


\section{Referências}

ASSOCIAÇÃO BRASILEIRA DE FLORESTAS PLANTADAS - ABRAF. Anuário Estatístico da ABRAF. Ano base 2008. Brasília, ABRAF, 2009. 129p.

Disponível em: http://www.abraflor.org.br/estatisticas/ABRAF09-BR.pdf. Acesso em: 30 jan. 2010.

BARROSO, Mario. Duas novas frentes desmatam áreas mais preservadas do bioma. Portal do agronegócio. Disponível em: http://portal.seagro.go.gov.br/index.php?act=cnt\&opt=1,9844. Acesso em: $28 \mathrm{dez}$. 2009.

BRASIL. Instituto Brasileiro de Geografia e Estatística - IBGE: levantamento sistemático da produção agrícola. Rio de Janeiro: IBGE, 2009. Disponível em: http://www.ibge.gov.br/home/estatistica/indicadores/agropecuaria/lspa/default.shtm.

Acesso em: 28 dez. 2009.

BORÉM, A.; SANTOS, F.R. Biotecnologia Simplificada. Viçosa: Ed. UFV, 2001.

DIEGUES, Antônio Carlos, at all (Org.). Os saberes tradicionais e a biodiversidade no Brasil. São Paulo: NUPAUB, 2002. Disponível: http://www.usp.br/nupaub/publica0.html. Acesso em: 28 ago. 2008.

DREW, David. Processo interativos homem-meio ambiente. Tradução de João Alves dos Santos. Revisão de Suely Bastos. São Paulo: DIFEL, 1986. 206p.

FIDELIS Alex Camargo; LIMA João Donizete. Impactos ambientais da silvicultura no bioma cerrado. Disponível em: http://www.uff.br/vsinga/trabalhos/Trabalhos\%20Completos/Alex\%20Camargo\%20Fid elis.pdf. Acesso em: 15 jan. 2010.

GOIÁS. Agência Ambiental do Estado de Goiás. Portaria 14/ 2001. Disponível em: http://www.ibracego.org.br/Default.asp?area=meio_ambiente\#goias. Acesso em: 28 dez. 2009.

GARLIPP, José Rubens Damas. O agronegócio nas terras de Goiás. EconomiaEnsaios, Uberlândia (MG). v. 19, n. 2, p. 143-146, jul. 2005. Resenha. Disponível em: http://www.seer.ufu.br/index.php/revistaeconomiaensaios/article/viewFile/1545/1371. Acesso em: 28 dez. 2009.

INSTITUTO SOCIEDADE, POPULAÇÃO E NATUREZA - ISPN. Cana de açúcar avança sobre áreas prioritárias para conservação do Cerrado. Brasília: ISPN, 2007. Disponível em: <http://www.ispn.org.br/LevantamentoSite.pdf.>. Acesso em: 15 out. 2009.

SANO, E. E.; DAMBROS, L. A.; OLIVEIRA, G. C.; BRITES, R. S. . Padrões de cobertura de solos do Estado de Goiás. In: Ferreira, L.G.. (Org.). A Encruzilhada Socioambiental: biodiversidade, economia e sustentabilidade no cerrado. Goiânia: Ed. da UFG, 2008. p. 91-106. 
SANTILLI, Juliana. Agrobiodiversidade e direito dos agricultores. São Paulo: Perópolis, 2009. 517p.

SILVEIRA, José Maria F. J. da; BORGES, Izaias de Carvalho e BUAINAIN, Antônio Márcio. Biotecnologia e agricultura: da ciência e tecnologia aos impactos da inovação. São Paulo em Perspectiva, v. 19, n. 2, p. 101-114, abr./jun. 2005. Disponível em: http://www.scielo.br/pdf/spp/v19n2/v19n2a09.pdf .Acesso em: 28 dez. 2009.

VALOIS, Afonso Celso Caldeira. Importância dos transgênicos para a agricultura. Caderno de Ciência \& Tecnologia, Brasília, v. 18, n.1, p. 27-53, jan.-abr. 2001. Disponível em: http://webnotes.sct.embrapa.br/pdf/cct/v18/cc18n102.pdf. Acesso em: 15 out. 2009.

Recebido para publicação em janeiro de 2010

Aprovado para publicação em março de 2010 